\title{
Glycogen synthase kinase $3 \beta$ represses MYOGENIN function in alveolar rhabdomyosarcoma
}

\author{
MG Dionyssiou ${ }^{1}$, S Ehyai ${ }^{1}$, E Avrutin ${ }^{2}$, MK Connor ${ }^{2}$ and JC McDermott ${ }^{\star 1,1,3,45}$
}

MYOGENIN is a member of the muscle regulatory factor family that orchestrates an obligatory step in myogenesis, the terminal differentiation of skeletal muscle cells. A paradoxical feature of alveolar rhabdomyosarcoma (ARMS), a prevalent soft tissue sarcoma in children arising from cells with a myogenic phenotype, is the inability of these cells to undergo terminal differentiation despite the expression of MYOGENIN. The chimeric PAX3-FOXO1 fusion protein which results from a chromosomal translocation in ARMS has been implicated in blocking cell cycle arrest, preventing myogenesis from occurring. We report here that PAX3-FOX01 enhances glycogen synthase kinase $3 \beta$ (GSK3 $\beta$ ) activity which in turn represses MYOGENIN activity. MYOGENIN is a GSK3 $\beta$ substrate in vitro on the basis of in vitro kinase assays and MYOGENIN is phosphorylated in ARMS-derived RH30 cells. Constitutively active GSK3 $\beta($ S9A) increased the level of a phosphorylated form of MYOGENIN on the basis of western blot analysis and this effect was reversed by neutralization of the single consensus GSK3 $\beta$ phosphoacceptor site by mutation (S160/164A). Congruently, GSK3 $\beta$ inhibited the trans-activation of an E-box reporter gene by wild-type MYOGENIN, but not MYOGENIN with the S160/164A mutations. Functionally, GSK3 $\beta$ repressed muscle creatine kinase (MCK) promoter activity, an effect which was reversed by the S160/164A mutated MYOGENIN. Importantly, GSK3 $\beta$ inhibition or exogenous expression of the S160/164A mutated MYOGENIN in ARMS reduced the anchorage independent growth of RH30 cells in colony-formation assays. Thus, sustained GSK3 $\beta$ activity represses a critical regulatory step in the myogenic cascade, contributing to the undifferentiated, proliferative phenotype in alveolar rhabdomyosarcoma (ARMS).

Cell Death and Disease (2014) 5, e1094; doi:10.1038/cddis.2014.58; published online 27 February 2014

Subject Category: Cancer

Rhabdomyosarcoma (RMS) is the most common pediatric soft tissue sarcoma, accounting for $5 \%$ of all childhood cancers and approximately $50 \%$ of soft tissue sarcomas. ${ }^{1-3}$ There are two main subtypes: embryonal and alveolar RMS and although embryonal RMS is more common, alveolar RMS is considered to carry a worse prognosis. A gene fusion resulting in the $t(2 ; 13)(q 35 ; q 14)$ somatic cell chromosomal translocation fuses $P A X 3$ and Foxo1 to create a potent transcription factor (PAX3-FOXO1) which is a predominant causative genetic lesion for the development of alveolar rhabdomyosarcoma (ARMS). ${ }^{1}$ ARMS is a highly malignant mesenchymal tumor that has properties of immature striated muscle tissue resulting in dense aggregates of poorly differentiated cells that are separated by fibrous membranes resulting in a loss in cellular cohesion. ${ }^{2,3}$ PAX3 is a key determinant of somatic myogenesis and, is involved in the migration of progenitor cells to the dermomyotome region of the somite where they grow and divide in the presence of growth factors. ${ }^{4}$ PAX3 is also required to activate the myogenic determination gene, MYOD. ${ }^{5}$ MYOD is one of four myogenic regulatory factors (MRFs, which include MYF-5, MRF4 and MYOGENIN) from the basic helix-loop-helix superfamily of transcription factors which interact with myocyte enhancer factor-2 (MEF2) proteins in the hierarchical control of muscle-specific gene expression. ${ }^{6}$ Two kinases that potently exert effects on this myogenic regulatory cascade are p38 mitogen activated protein kinase (MAPK) and glycogen synthase kinase $3 \beta($ GSK3 $\beta)$. p38 MAPK is a key regulator of skeletal myogenesis that critically interacts with and activates MEF2 in the somite myotome during development. ${ }^{7-9}$ Conversely, GSK3 $\beta$ activation leads to a repression in skeletal and cardiac muscle differentiation, in part by antagonizing p38 MAPK-mediated activation of MEF2. ${ }^{10,11}$ GSK3 $\beta$ usually targets proteins that have already been phosphorylated by another kinase at a 'priming' serine or threonine residue located four amino acids C-terminal to a consensus $(\mathrm{S} / \mathrm{T}) \mathrm{XXX}(\mathrm{S} / \mathrm{T})-\mathrm{PO}_{4}$ motif. $^{12,13}$ Regulation of MEF2 and the MRFs leads to morphological changes including epithelial to mesenchymal transition, cell alignment and fusion to form multinucleated myotubes that eventually develop into

\footnotetext{
${ }^{1}$ Department of Biology, York University, 4700 Keele Street, Toronto, Ontario M3J 1P3, Canada; ${ }^{2}$ Department of Kinesiology, York University, 4700 Keele Street, Toronto, Ontario M3J 1P3, Canada; ${ }^{3}$ Centre for Research in Mass Spectrometry, York University, Toronto, Ontario M3J 1P3, Canada; ${ }^{4}$ Muscle Health Research Centre, York University, Toronto, Ontario M3J 1P3, Canada and ${ }^{5}$ Centre for Research in Biomolecular Interactions, York University, Toronto, Ontario M3J 1P3, Canada ${ }^{*}$ Corresponding author: JC McDermott, Department of Biology, York University, 4700 Keele Street, Toronto, Ontario M3J 1P3, Canada. Tel: +1 416 7362100 ; Fax: +1 416736 2100; E-mail: jmcderm@yorku.ca

Keywords: alveolar rhabdomyosarcoma; PAX3-FOXO1; MYOGENIN; GSK3 $\beta$; cell proliferation; tumorigenicity

Abbreviations: GFP, green fluorescent protein; GSK3 $\beta$, glycogen synthase kinase $3 \beta$; Luc, luciferase; MAPK, mitogen activated protein kinase; MCK, muscle creatine kinase; MEF2, myocyte enhancer factor-2; PI3K, phosphoinositide 3-kinase; PKB, protein kinase B

Received 05.11.13; revised 20.1.14; accepted 21.1.14; Edited by A Stephanou
} 


\section{a}
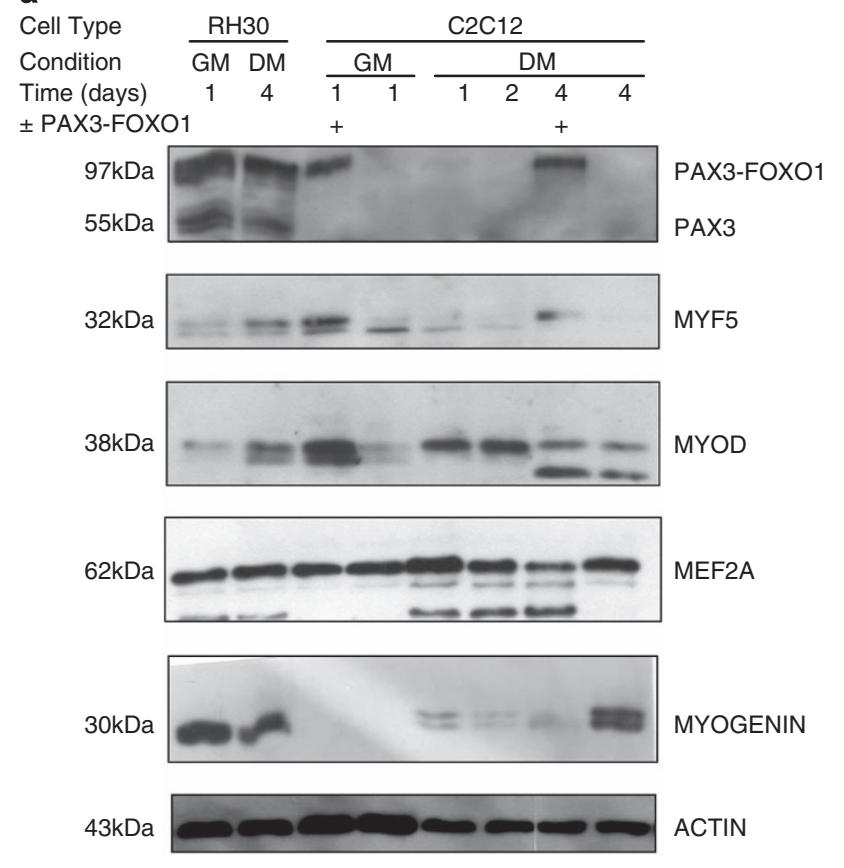

b
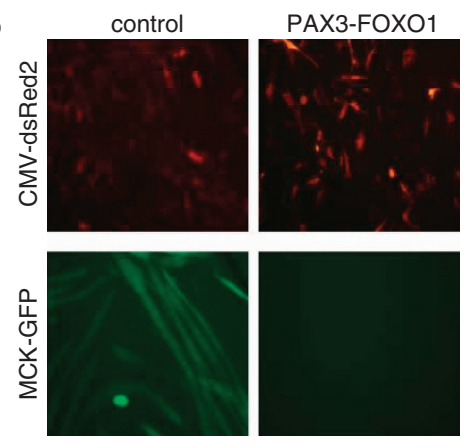

c

cell type: $\mathrm{C} 2 \mathrm{C} 12 \mathrm{RH} 30 \mathrm{RD}$
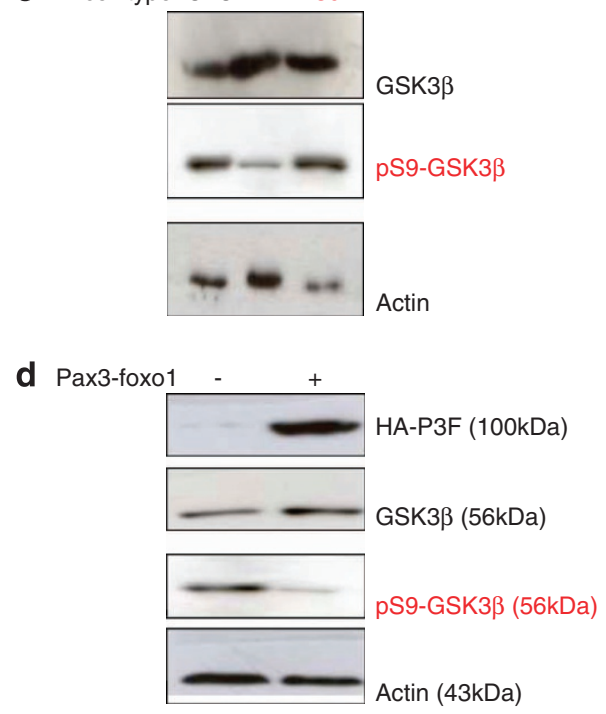

functional, contractile muscle fibers. In particular, cells that express MYOD and MYOGENIN are typically fusion competent ${ }^{14,15}$ with the exception of ARMS cell types. To date, lack of myogenic differentiation of PAX3-FOXO1 expressing ARMS cells has been attributed to their inability to upregulate p57 ${ }^{\text {Kip2 }}$ activity, hence destabilizing the DNA binding affinity of MYOD transcription complexes. ${ }^{16}$ Dysfunctional MYOD/Eprotein complex association and transcriptional control is a common feature between ARMS and the non-PAX3-FOXO1 expressing embryonal rhabdomyosarcoma (ERMS). Subsequent restoration of the MYOD/E12 complex has been shown to switch ERMS cells from an arrested myofibroblast phase to a more differentiated state. ${ }^{17}$ Similarly p38 MAPK activity can potentiate myogenic differentiation in ERMS cells by enhancing MYOD trans-activation properties. ${ }^{18}$ Therefore, it is fairly clear that in both rhabdomyosarcoma subtypes the ability of MYOD to potentiate transcription is compromised. However, the role of MYOGENIN in RMS is more equivocal. For normal myogenesis to occur, both in vitro and in vivo, an absolute requirement for MYOGENIN is evident. Thus, MYOGENIN activity constitutes a pivot point for irreversible commitment to terminal differentiation. ${ }^{19,20}$ The combination of data from gene targeting studies of the MRFs ${ }^{21,22}$ supports the prevailing consensus that while the other three MRFs can compensate each other's functional roles, ${ }^{23-26}$ MYOGENIN is absolutely essential for skeletal muscle fiber formation. ${ }^{20}$ Despite its expression in RMS, the paradox as to why MYOGENIN cannot mediate competence for differentiation is unknown.

Here, we examined the posttranslational regulation of MYOGENIN in ARMS. On the basis of the in silico prediction of a single consensus phosphorylation site for GSK3 $\beta$ on the MYOGENIN protein and also high levels of GSK3 $\beta$ activity in these cells, we determined that MYOGENIN function is potently repressed by GSK3 $\beta$ activity in ARMS. Moreover, pharmacological inhibition of GSK3 $\beta$ results in a profound decrease in size and, to a certain extent, number of RMS colonies in a colony-formation assay. This effect is mimicked by introduction of MYOGENIN bearing neutralizing mutations in the GSK3 $\beta$ consensus site. In combination, these data reveal MYOGENIN as a key target of GSK3 $\beta$ activity in

Figure 1 MYOGENIN protein expression and GSK3 $\beta$ activity are both maintained in ARMS: (a) C2C12 myoblasts were transfected with HA-PAX3FOXO1 or pcDNA3.1 control plasmid for 1 day before extraction or serum withdrawal and then extraction at 1 day increments for up to 4 days as indicated. Protein levels were compared with protein extracts from PAX3-FOXO1 expressing RH30 cells 1 day in growth media (GM) and 4 days in differentiation media (DM). The results show that despite the expression of PAX3-FOXO1, RH30 cells also express MYOGENIN. On the other hand, HA-PAX3-FOXO1 overexpression in C2C12 inhibits MYOGENIN expression and subsequent myogenic differentiation. (b) $\mathrm{C} 2 \mathrm{C} 12$ myoblasts were transfected with CMV-dsRed2, MCK-eGFP and, either HA-PAX3-FOXO1 or pcDNA3.1 control plasmid. HA-PAX3-FOXO1 overexpression repressed the formation of multinucleated myotubes. (c) Endogenous GSK3 $\beta$ protein levels and phosphorylation at serine 9 were compared in $\mathrm{C} 2 \mathrm{C} 12$ myoblasts, $\mathrm{RH} 30$ and ERMS RD cells. Although GSK3 $\beta$ is expressed in all three cell types, it is predominantly phosphorylated and hence inactive in $\mathrm{C} 2 \mathrm{C} 12$ myoblasts and RD cells but not PAX3-FOXO1 expressing RH30 cells. (d) $\mathrm{C} 2 \mathrm{C} 12$ myoblasts were transfected with HA-PAX3-FOXO1 or pcDNA3.1 control plasmid for 1 day before extraction. Overexpression of HA-PAX3-FOXO1 resulted in decreased phosphorylation of GSK3 $\beta$ at serine 9 indicating its activation 
ARMS, indicating that pharmacologic manipulation of this signaling axis may provide an opportunity for therapeutic intervention.

\section{Results}

MYOGENIN is expressed in PAX3-FOXO1 expressing RH30 cells. Serum (10\% FBS) contains growth factors that repress the transcriptional activity of MRFs and also stimulate cell cycle progression hence rendering $\mathrm{C} 2 \mathrm{C} 12$ myoblasts proliferative. In tissue culture, serum withdrawal $(2 \% \mathrm{HS})$ results in activation of MEF2 and MRFs causing cell alignment and fusion to form multinucleated myotubes. Initially, in order to investigate the effect of PAX3-FOXO1 on this differentiation program, proliferating $\mathrm{C} 2 \mathrm{C} 12$ myoblasts were transiently transfected with CMV-dsRed2, MCK-eGFP, and either HA-PAX3-FOXO1 or pcDNA3.1 control vector. Growth media (GM) was replaced with differentiation media (DM) $19 \mathrm{~h}$ after transfection and cells were allowed to differentiate for $96 \mathrm{~h}$. SDS-PAGE samples were prepared from populations of myoblasts that either expressed or did not express PAX3-FOXO1, (a) before serum withdrawal (time $=0 ; \mathrm{GM}=10 \% \mathrm{FBS}$ ) and (b) at $24 \mathrm{~h}$ increments upon serum withdrawal (days 1-4; $\mathrm{DM}=2 \% \mathrm{HS}$ ). Protein expression levels of these samples were then compared with protein samples from PAX3-FOXO1 expressing RH30 cells in GM and DM, by western blotting. These data indicate that despite the expression of PAX3-FOXO1, MYOGENIN protein expression is maintained in human ARMS-derived $\mathrm{RH} 30$ cells (Figure 1a). In addition, PAX3FOXO1 repressed myotube formation in C2C12 myoblasts (Figures 1a and b). Detection of myogenic differentiation using an MCK promoter driving GFP expression ${ }^{27}$ revealed GFP expressing, multinucleated myotubes in the controls but not in cells expressing PAX3-FOXO1 (Figure 1b).

It is well documented that MRFs and MEF2 proteins are highly sensitive to pro-myogenic kinases such as p38 MAPK $^{9,28-30}$ and also kinases such as GSK3 $\beta$ which are
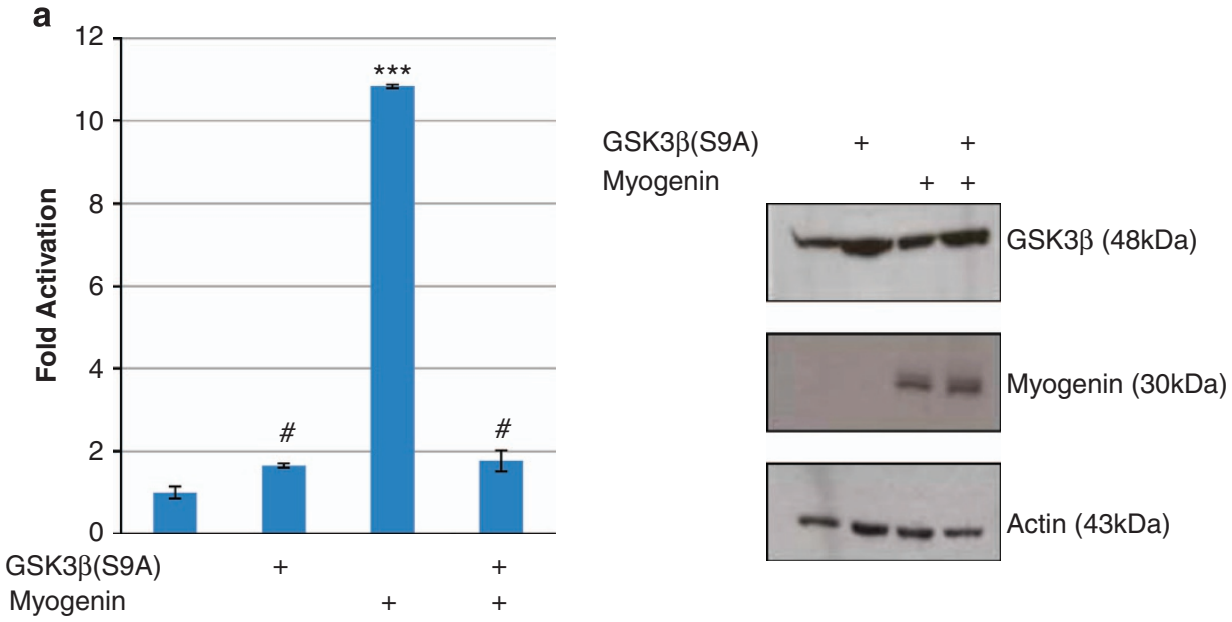
b GST-Myogenin MyBP GST GSK3 $\beta$
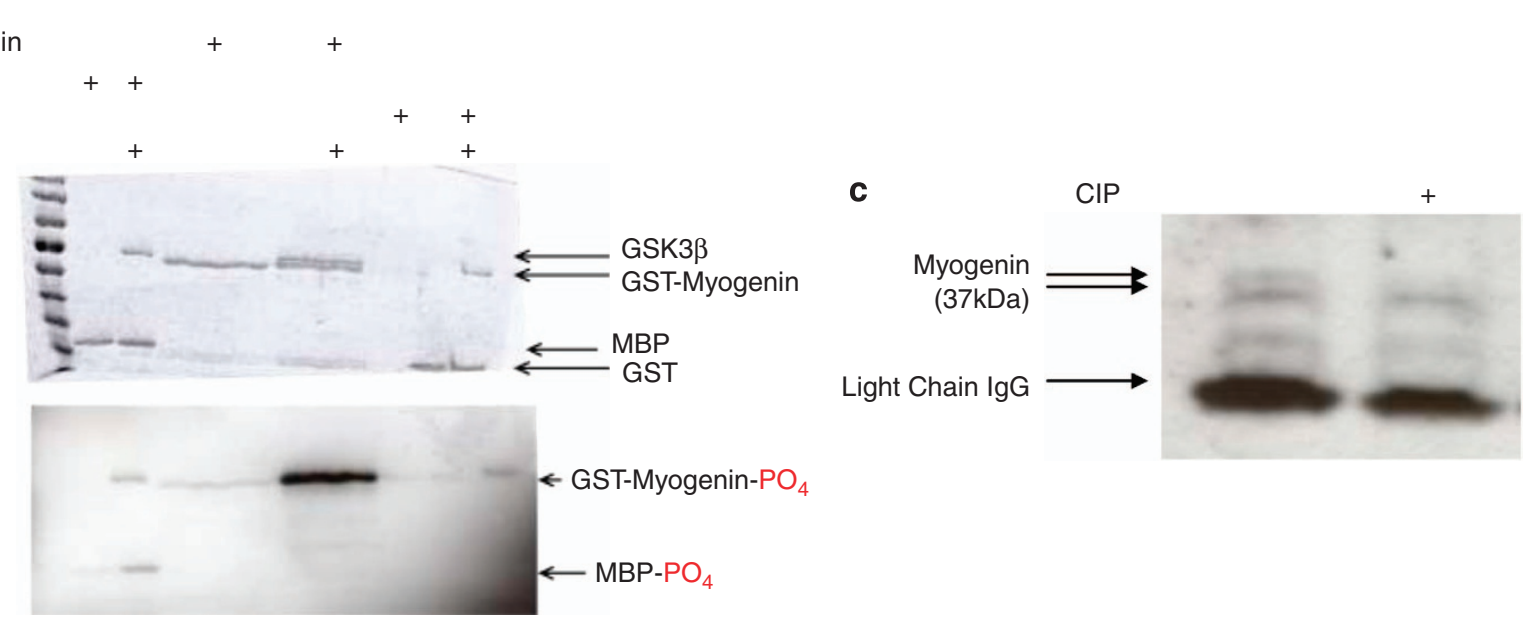

Figure 2 Overexpressed, constitutively active GSK3 $\beta(\mathrm{S} 9 \mathrm{~A})$ represses MYOGENIN trans-activation of E-box. (a) C2C12 myoblasts were transfected with 4x E-box Luc reporter and different combinations of HA-GSK3 $\beta($ S9A) and MYOGENIN or pcDNA3.1 control plasmid as indicated. Overexpressed HA-GSK3 $\beta$ (S9A) repressed MYOGENIN transcriptional activity $(P<0.001)$. (b) GSK3 $\beta$ directly phosphorylates MYOGENIN in vitro: Purified GST-MYOGENIN was incubated in vitro with GST-GSK3 $\beta$ and $\left(\gamma^{32}\right.$ P) ATP. GST and MBP proteins were used as negative and positive control respectively as indicated. Bands were resolved using SDS-PAGE and visualized by Coomassie Blue staining. Gels were dried and exposed to X-ray film for $21 \mathrm{~h}$ after the assay. (c) Calf-intestinal phosphatase (CIP) treatment of immunoprecipitated MYOGENIN that was obtained from $1000 \mu \mathrm{g}$ of $\mathrm{RH} 30$ protein extract. The data shows that CIP treatment causes a loss of a high-molecular weight, phosphorylated form of MYOGENIN. ${ }^{*} \mathrm{~ns},{ }^{* \star *} P<0.001$ 
repressive to myogenesis. ${ }^{10,31}$ Therefore we tested for GSK3 $\beta$ activity under conditions when myogenesis is supressed. As GSK3 $\beta$ is constitutively active until it is repressed by phosphorylation at serine 9 (by PKB), we assessed both total GSK3 $\beta$ protein expression levels and S9 phosphorylation levels using appropriate antibodies as indicated. We document that GSK3 $\beta$ is expressed in proliferative $\mathrm{C} 2 \mathrm{C} 12$ myoblasts, PAX3-FOXO1 expressing ARMS cells $(\mathrm{RH} 30)$ and, non-PAX3-FOXO1 ERMS cells (RD). However only in PAX3-FOXO1 expressing RH30 cells, is GSK3 $\beta$ predominantly in its unphosphorylated form (at serine 9) and, hence fully active state (Figure 1c). In addition, ectopic expression of PAX3-FOXO1 resulted in reduced phosphorylation of GSK3 $\beta$ at serine 9 in $\mathrm{C} 2 \mathrm{C} 12$ myoblasts (Figure 1d).

MYOGENIN trans-activation function is repressed by GSK3 $\beta$. To assess the effect of GSK3 $\beta$ activity on MYOGENIN function, trans-activation of a $4 x$ E-box Luciferase construct was measured in proliferating $\mathrm{C} 2 \mathrm{C} 12$ myoblasts that were transfected with different combinations of constitutively active GSK3 $\beta$ (S9A) and MYOGENIN as indicated in Figure $2 a$. The data indicate that MYOGENIN potentiates the 4x E-box Luc reporter gene and that GSK3 $\beta(\mathrm{S} 9 \mathrm{~A})$ abrogates this effect $(P<0.001)$ indicating repression of MYOGENIN by active GSK3 $\beta$ (Figure 2a, left panel) without affecting the MYOGENIN protein expression levels (Figure $2 a$, right panel).

GSK3 $\beta$ directly phosphorylates MYOGENIN in vitro. In order to determine whether MYOGENIN is a substrate for GSK3 $\beta$, an in vitro kinase assay was performed using GSTMYOGENIN (1-225), purified GST-GSK3 $\beta$ and $\gamma-{ }^{32} \mathrm{P}$ ATP. Bands were resolved using SDS-PAGE and subsequent autoradiography showed ${ }^{32} \mathrm{P}$ labeled bands for MYOGENIN, autophosphorylated GSK3 $\beta$ and MyBP (positive control, Figure $2 \mathrm{~b}$ ). In addition, Coomassie Blue staining revealed a lower mobility band indicative of phosphorylation (Figure $2 b$ ). To further test the idea that the lower mobility band is hyperphosphorylated, we used calf-intestinal phosphatases on $\mathrm{RH} 30$ cell lysates and found that the low mobility band was eradicated (Figure 2c). Collectively these data suggest that MYOGENIN is a GSK3 $\beta$ substrate in vitro.

Pharmacologic manipulation of GSK3 $\beta$ activity alters MYOGENIN properties. To further investigate the effect of GSK3 $\beta$ on MYOGENIN, COS7 cells were co-transfected with MYOGENIN and GSK3 $\beta(\mathrm{S} 9 \mathrm{~A})$ and, then treated with or without $10 \mu \mathrm{M}$ GSK3 $\beta$ inhibitor, AR-A014418, as indicated in Figures $3 a$ and $b$. Western blot analysis revealed two predominant forms of MYOGENIN, a low mobility hyperphosphorylated isoform and a high mobility, hypophosphorylated isoform (Figure 3a, lane 2). The lower mobility, hyperphosphorylated band is reduced upon pharmacological treatment with AR-A014418 as indicated (Figure 3a, lane 3). This corresponded with a significant increase in transactivation of an E-box cis element driven reporter gene $(P<0.001$, Figure $3 \mathrm{~b})$. In contrast, constitutively active GSK3 $\beta$ (S9A) without pharmacological inhibition resulted in an increase in the low mobility, hyperphosphorylated band
(Figure 3a, lane 4) which corresponded to a decrease in E-box luciferase activity in reporter gene assays $(P<0.05$, Figure 3b).

Mutation of a consensus GSK3 $\beta$ phosphoacceptor site on MYOGENIN (S160/164A) prevents GSK3 $\beta$-mediated repression. By in silico analysis, MYOGENIN contains a highly conserved putative GSK3 $\beta$ consensus phosphoacceptor site (Table 1), which we targeted by neutralizing site-directed mutagenesis. We observed that although wild-type MYOGENIN is sensitive to the repressive effects of constitutively active GSK3 $\beta($ S9A), MYOGENIN
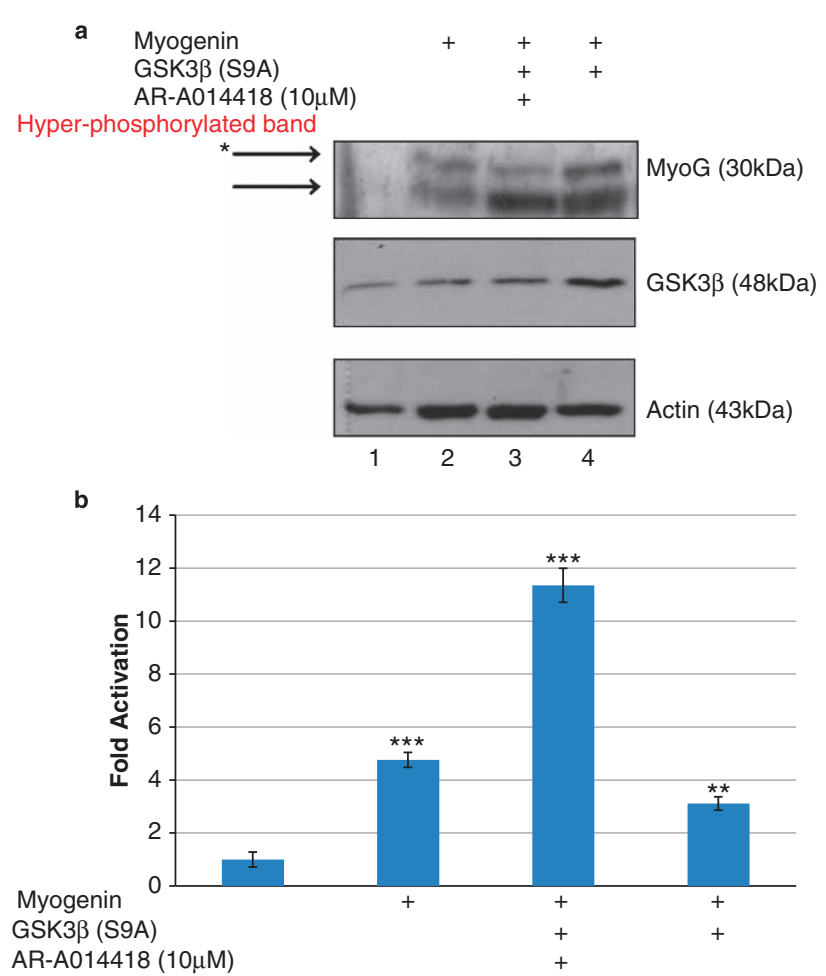

Figure 3 GSK3 $\beta$ increases MYOGENIN protein, possibly through phosphorylation and this corresponds with decreased transcriptional activity. (a) Cos7 cells were transiently transfected with or without MYOGENIN and/or GSK3 $\beta(\mathrm{S} 9 \mathrm{~A})$ and then treated for $19 \mathrm{~h}$ with either $10 \mu \mathrm{M}$ GSK3 $\beta$ inhibitor or DMSO $24 \mathrm{~h}$ after transfection as indicated. Protein samples were extracted and western blot analysis revealed an increase in a slower migrating, hyperphosphorylated MYOGENIN band (lane 4 ) in the presence of overexpressed HA-GSK3 $\beta(\mathrm{S} 9 \mathrm{~A})$, which was reduced in the presence of GSK3 $\beta$ inhibitor (lane 3). (b) E-box Luc reporter gene was co-transfected in Cos7 cells using the same conditions that were described above. Overexpressed MYOGENIN significantly enhanced transcriptional activity of the E-box promoter $\left({ }^{* * \star} P<0.001\right)$ and, this effect was further increased in the presence of GSK3 $\beta$ inhibitor despite overexpression of $\operatorname{GSK} 3 \beta(\mathrm{SgA}) \quad(P<0.001)$. Overexpression of GSK3 $\beta(\mathrm{S} 9 \mathrm{~A})$ repressed MYOGENIN transcriptional activity $\left({ }^{* \star} P<0.05\right)$

Table 1 GSK3 $\beta$ consensus sequence within Myogenin

\begin{tabular}{lc}
\hline Myogenin sequence: & Species: \\
\hline 158 VPSECSSHSASCSP 171 & Human \\
158 VPSECNSHSASCSP 171 & Mouse \\
158 VPSECNSHSASCSP 171 & Rat \\
\hline
\end{tabular}


a

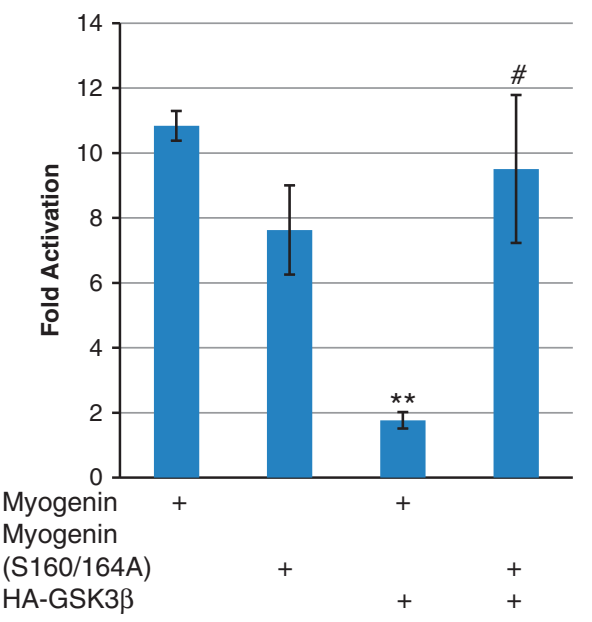

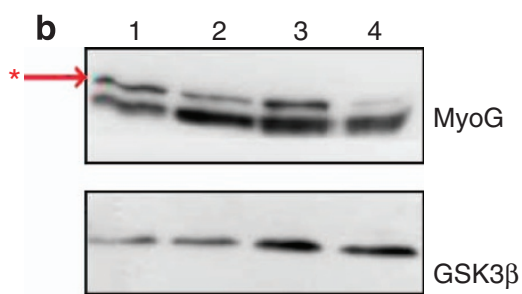
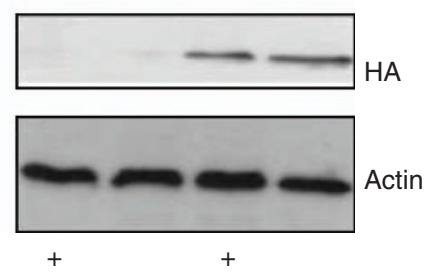

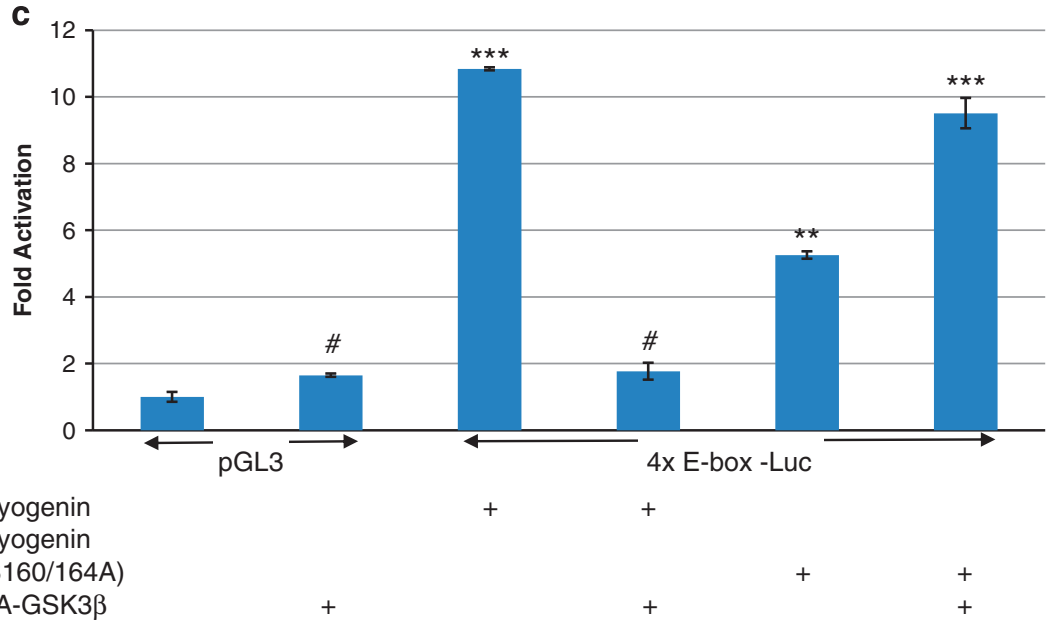

Figure 4 MYOGENIN neutralizing phosphomutant (S160/164A) is resistant to GSK3 $\beta$ repression of transcription activity as well as an increased slower migrating, hyperphosphorylated MYOGENIN band. (a) 4x E-box Luc activity was assessed in C2C12 myoblasts that were transfected with either wild-type MYOGENIN or MYOGENIN (S160/164A) and, co-transfected with HA-GSK3 $\beta(S 9 A)$ or pcDNA3.1 control plasmid as indicated. HA-GSK3 $\beta(S 9 A)$ repressed MYOGENIN trans-activation of the 4x E-box promoter region $(P<0.001)$ but had no effect on mutated MYOGENIN $(S 160 / 164 A)$ transcriptional activity. (b) Western blot analysis of the same samples revealed a decrease in a slower migrating, hyperphosphorylated band for overexpressed MYOGENIN (S160/164A, lane 2) with respect to overexpressed wild-type MYOGENIN (lane 1). Co-transfected HA-GSK3 $\beta(\mathrm{S} 9 \mathrm{~A})$ caused an increase in the slow migrating, hyperphosphorylated MYOGENIN band (lane 3) but not with overexpressed mutated MYOGENIN (S160/164A, lane 4). (c) Independent analysis of E-box Luc activity in C2C12 myoblasts with different combinations of overexpressed MYOGENIN, mutated MYOGENIN (S160/164A), HA-GSK3 $\beta(\mathrm{S} 9 \mathrm{~A})$ or pcDNA3.1 control plasmid as indicated. ${ }^{* *} P<0.001,{ }^{* *} P<0.05$, $\mathrm{ns}$

(S160/164A) was not (Figure 4a). Western blot analysis revealed that MYOGENIN (S160/164A) mutations correspond with a decrease in the low mobility, hyperphosphorylated upper band (Figure $4 \mathrm{~b}$, lane 2) and that this effect was not altered by ectopically expressed HAGSK3 $\beta$ (S9A). Together these data indicate that S160/164A mutations in MYOGENIN render it insensitive to the repressive effect of GSK3 $\beta$. GSK3 $\beta(\mathrm{S} 9 \mathrm{~A})$ expression resulted in an increase in the low mobility, hyperphosphorylated form of wild-type MYOGENIN (Figure $4 \mathrm{~b}$, lane 3) and this corresponded with decreased E-box luciferase activity $(P<0.001$, Figure $4 a)$. Although trans-activation of the skeletal muscle gene E-box cis-element by mutated MYOGENIN (S160/164A) is marginally less potent than wild-type MYOGENIN ( $P<0.05$, Figure $4 \mathrm{c})$; it is resistant to inhibition by activated GSK3 $\beta(P<0.001$, Figure $4 \mathrm{c})$.
PAX3-FOXO1 activation of GSK3 $\beta$ antagonizes muscle creatine kinase promoter activation. To further examine the functional significance of our findings, we used MCK promoter activity, as a key indicator of the activation of myogenic differentiation, in $\mathrm{C} 2 \mathrm{C} 12$ myoblasts that were transfected with or without the PAX3-FOXO1 oncogene (Figure 5a). These data depict that PAX3-FOXO1 represses MCK promoter activation in myoblasts that have been co-transfected with MYOGENIN $(P<0.01)$ and this effect is not only abrogated by pharmacological inhibition of GSK3 $\beta$, but further activated $(P<0.001$, Figure $5 a)$. Interestingly, in PAX3-FOXO1 expressing, human ARMS-derived $\mathrm{RH} 30$ cells, ectopically expressed MYOGENIN had no effect on MCK promoter activity unless it was coupled with pharmacological inhibition of GSK3 $\beta$ using AR-A014418 $(P<0.001$, Figure 5b). Conversely, mutated MYOGENIN (S160/164A) 


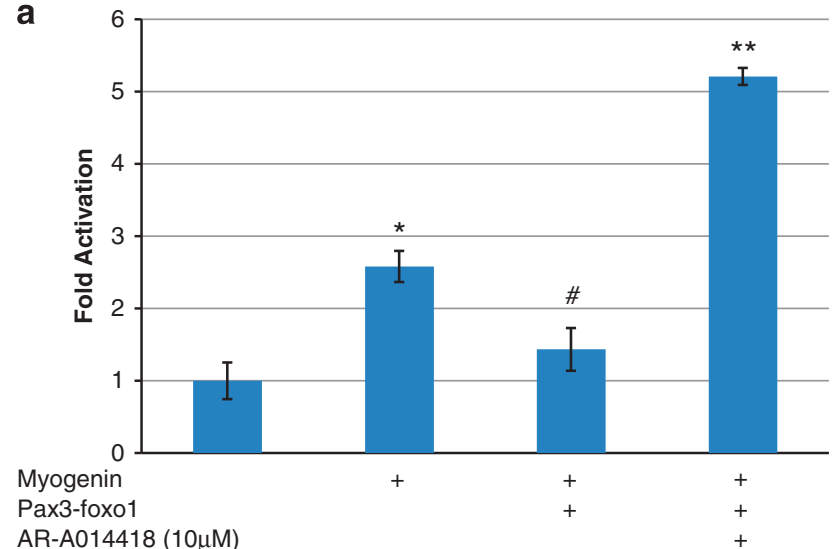

b

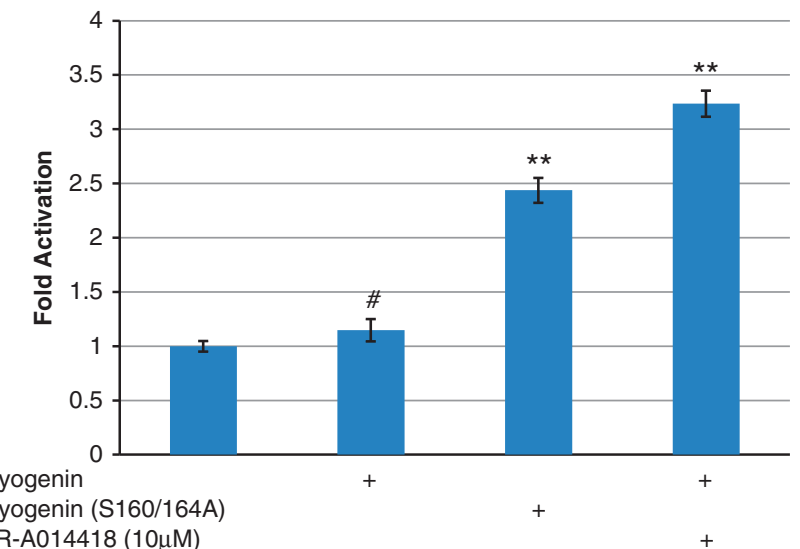

AR-A014418 (10uM)

Figure 5 Pharmacological inhibition of GSK3 $\beta$ rescues PAX3-FOXO1 repression of MYOGENIN's transcriptional activation of MCK promoter in both C2C12 myoblasts and RH30 human ARMS cells. (a) MCK-Luc promoter activity was assessed in $\mathrm{C} 2 \mathrm{C} 12$ myoblasts that were transfected with different combinations of MYOGENIN, PAX3-FOXO1 and pcDNA3.1 control plasmid as indicated and then treated with either $10 \mu \mathrm{M}$ AR-A014418 or DMSO solvent. MYOGENIN enhanced MCK-Luc activity as expected $(P<0.001)$ and this effect was repressed by co-expression of PAX3-FOXO1 $(P<0.01)$. Pharmacological inhibition of GSK3 $\beta$ not only reversed the effect of PAX3-FOXO1 but resulted in a super-activation $(P<0.001)$. (b) To assess the importance of these findings in human-derived ARMS, RH30 cells were transfected with either MYOGENIN or mutated MYOGENIN(S160/164A) and MCK-Luc promoter activity was assessed. The data shows that wild-type MYOGENIN could not trans-activate the MCK promoter region unless it was coupled with pharmacological inhibition of GSK3 $\beta$ $(P<0.001)$. This was in contrast to mutated MYOGENIN $(S 160 / 164 A)$, which could potentiate MCK promoter activity $(P<0.001)$ regardless of GSK3 $\beta$ inhibition. (c) Summary of our findings: GSK3 $\beta$ activity in ARMS represses the activation of muscle-specific genes by repressing the transcriptional activity of MYOGENIN. " $\mathrm{ns}$, ${ }^{\star} P<0.01,{ }^{*} P<0.001$

was able to potentiate MCK promoter activity regardless of GSK3 $\beta$ inhibition $(P<0.05$, Figure $5 b)$. Taken together, these data provide evidence that $\mathrm{S} 160 / 164$ on MYOGENIN are likely key targets of GSK3 $\beta$ signaling in alveolar rhabdomyosarcoma resulting in a diminution of the critical E-box dependent gene activation that is necessary and sufficient for differentiation.

Manipulation of GSK3 $\beta$ and MYOGENIN activity reduces tumorigenic properties of ARMS-derived RH30 cells. Colony-formation assays were performed as previously described using $\mathrm{RH} 30$ cells $^{32}$ which can grow in an anchorage independent manner. Equal numbers of $\mathrm{RH} 30$ cells that have been transiently transfected with or without MYOGENIN containing the S160/164A mutations were seeded in growth media with or without $10 \mu \mathrm{M}$ AR-A014418 (GSK3 $\beta$ inhibitor) and allowed to form colonies for 21 days (Figure 6). The addition of $10 \mu \mathrm{M}$ AR-A014418 significantly impaired the ability of RH30 cells to form colonies $(P<0.05)$ and remarkably reduced the size of the colonies $(P<0.0001)$. A similar reduction in colony numbers and size were also evident in RH30 cells that were transfected with MYOGENIN (S160/164A) mutations (Figures 6a and b). In addition, we confirmed that pharmacological inhibition of GSK3 $\beta$ significantly reduced cell proliferation of PAX3FOXO1 expressing cells (Figure 6c). Collectively these findings strongly indicate that GSK3 $\beta$ activity promotes the tumorigenicity of $\mathrm{RH} 30$ cells and that this effect is neutralized by expression of MYOGENIN bearing mutations that render it insensitive to GSK3 $\beta$.

Electrical stimulation of ARMS-derived RH30 cells reduces GSK3 $\beta$ activity through Akt (PKB). Electrical stimulation of skeletal muscle cells in cell culture has been shown to induce phenotype alterations and differentiation. ${ }^{33}$ Given that rhabdomyosarcoma shares properties of the skeletal muscle lineage, we electrically stimulated cultured RH30 cells for $4 \mathrm{~h} /$ day $(5 \mathrm{~Hz})$ for up to 4 days with the idea that it might promote differentiation by affecting the Akt/GSK3 $\beta$ signaling pathway. ${ }^{34}$ Stimulation of these cells resulted in an increase in pAktT308 to levels that were $3.00 \pm 0.72$-fold higher than those in non-stimulated cells after 4 days of stimulation (Figures $7 a$ and b). Concomitantly, pGSK $\beta$ S9 was also increased $2.25 \pm 0.37$ fold following 4 days of stimulation (Figures $7 a$ and $c$ ). These increases in pAktT308 and pGSK $\beta$ S9 were not a result of increases in total protein (Figure $7 \mathrm{a}$ ) as indicated by the $3.76 \pm 1.32$ and $2.05 \pm 0.55$ increases in relative phosphorylation, respectively (Figures $7 \mathrm{~d}$ and e). These changes in kinase activity corresponded with increased E-box promoter activity in stimulated cells compared with controls (Figure 7f). Collectively, these data indicate that electrical stimulation suppresses GSK3 $\beta$ activity and correspondingly activates MRF activity supporting our previous findings and also highlighting the possibility of using electrical stimulation as a therapeutic intervention in ARMS patients.

\section{Discussion}

ARMS, unlike ERMS, has a well-characterized cytogenetic basis in the majority of patients resulting from chromosomal translocations between chromosomes 1 and 13 and also 2 and 13 that result in fusion of the DNA binding domains of either Pax7 or PAX3 with the trans-activation domain of the Forkhead (FKHR) transcription factor family member Foxo1. ${ }^{1,2,35}$ In view of the well-substantiated crucial role of PAX3 and 7 in the development of skeletal muscle ${ }^{4,5}$ it is therefore not surprising that the signature of ARMS tumor cells is a muscle-like phenotype and the expression of a variety of structural muscle marker genes such as myosin heavy chain and desmin. ${ }^{36}$ What is surprising is the sustained expression of MYOD and MYOGENIN in ARMS, ${ }^{37,38}$ 
a

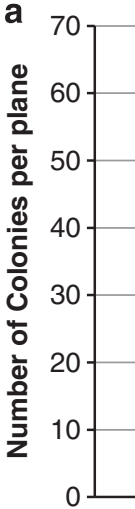

10 MM AR-A014418

MyoG(S160/164A)
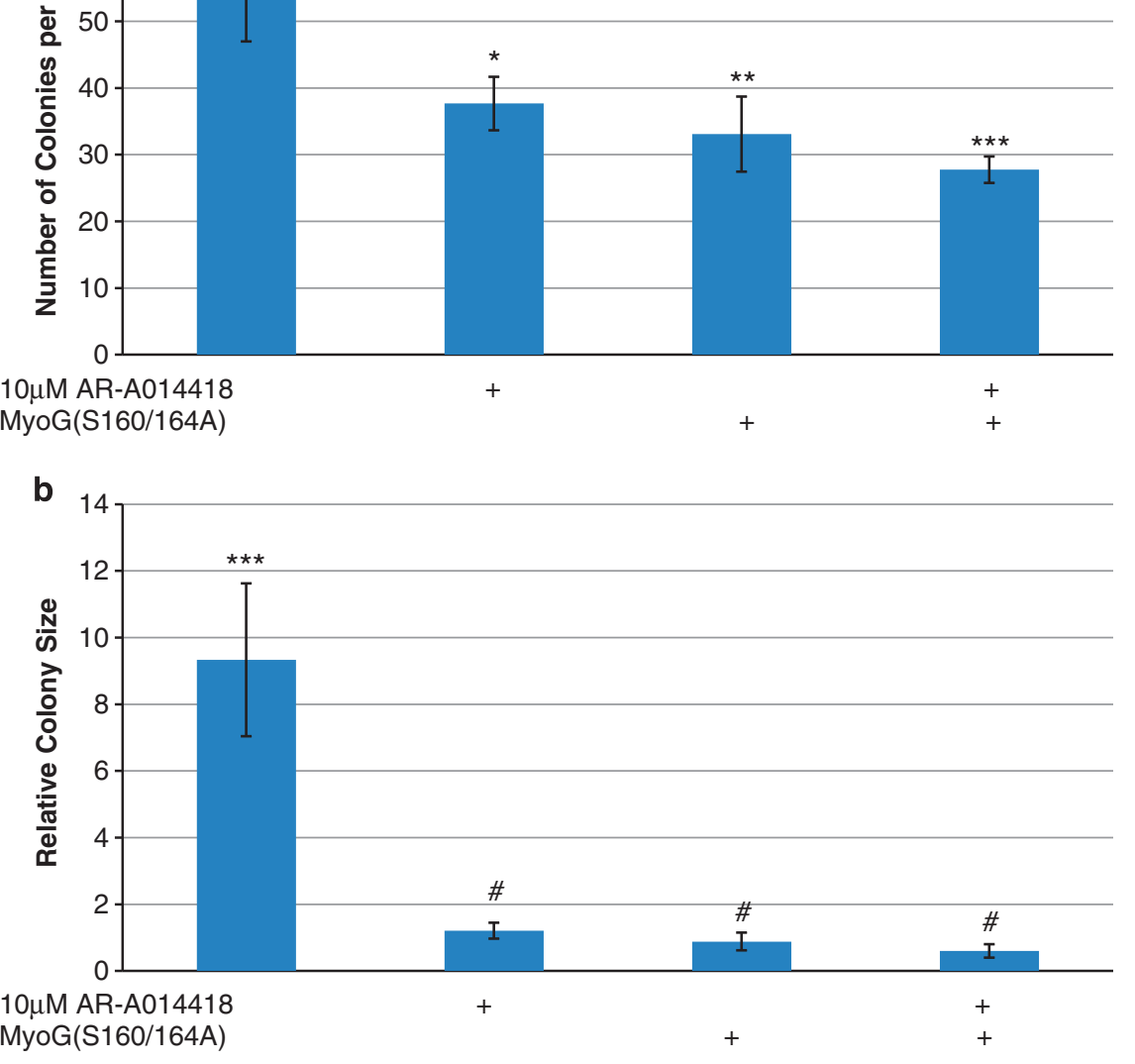

$10 \mu \mathrm{M}$ AR-A014418
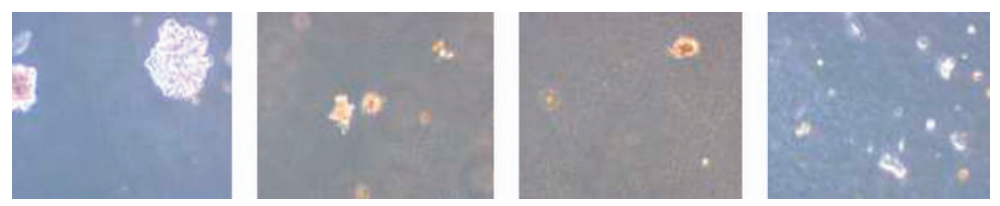

c

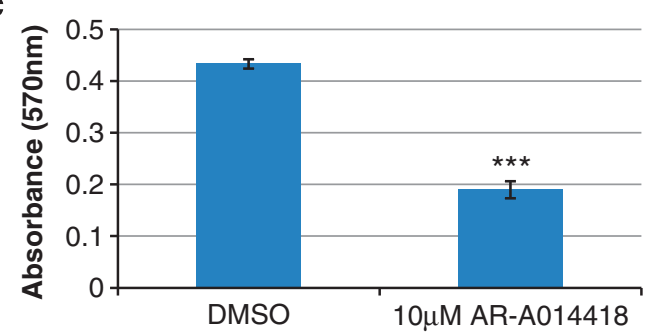

Figure 6 Soft agarose colony formation and MTT cell proliferation assays: (a) Equal numbers of RH30 cells were seeded under different conditions as depicted, and allowed to form colonies for 21 days. On the $22 n$ d day the colonies were stained with $0.005 \%$ Crystal Violet overnight. Colonies were counted at different planes $(n=10)$ in four independent experiments done in triplicate. The total number of colonies was reduced by (i) $10 \mu \mathrm{M}$ AR-A014418, $P<0.05$ (ii) Transient transfection of MYOGENIN containing the S160/164A neutralizing mutations, $P<0.01$ and (iii) both, $P<0.001$. Also see Supplementary Figure 1 for visual representation of the data. (b) We searched for the three largest colonies in each of the 12 plates for each condition and calculated the area using ImageJ software. The data revealed that the control colonies could grow up to $9 \times$ bigger than any of the experimental conditions, $P<0.001$. (c) MTT cell proliferation assays were performed in $P A X 3 / F O X 01 A$-expressing cells with and without $10 \mu \mathrm{M}$ AR-A014418 treatment. The experiment revealed that GSK3 $\beta$ inhibition reduces cell proliferation by $\sim 2$-fold, $P<0.001 .{ }^{\#} \mathrm{~ns},{ }^{*} P<0.05,{ }^{* *} P<0.01,{ }^{* \star *} P<0.001$

which are transcription factors that are intimately associated with the terminally differentiated, non- proliferative phenotype of normal myogenic cells, begging the question as to why they cannot exert this effect in ARMS. In particular, the function of MYOGENIN in the myogenic regulatory hierarchy places it at a pivotal and required step in the terminal commitment of myogenic progenitors to the differentiation program. ${ }^{19,20,34}$ Thus, our observations reported here, that MYOGENIN function in ARMS is repressed by inappropriate sustained signaling by the kinase GSK3 $\beta$, may be of considerable 
a

$$
\frac{0}{C} \frac{1}{C \quad S} \frac{2}{C \quad S} \frac{3}{C \quad S} \frac{4}{C \quad S}
$$

$\mathrm{pAkt}^{\mathrm{T} 308}$

Akt total

pGSK3 3 S9

GSK3 $\beta$ total

$\beta$-actin

b

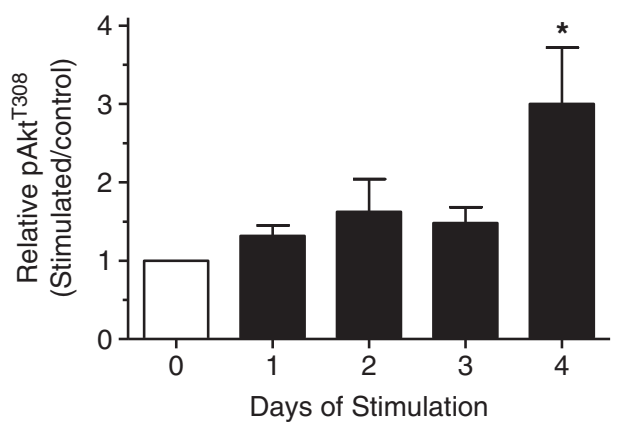

d

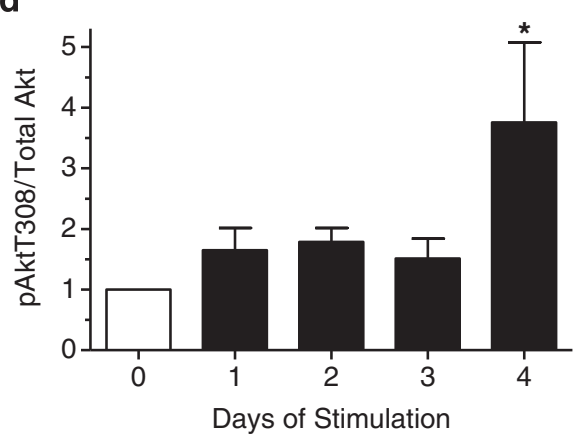

C

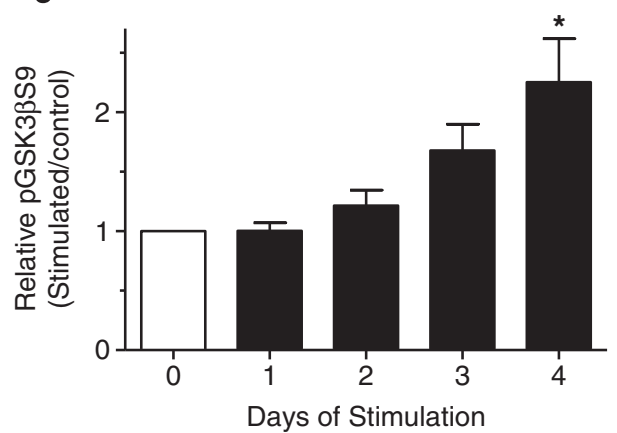

e

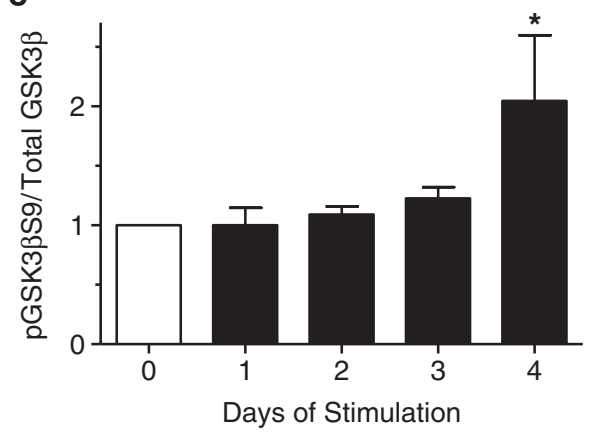

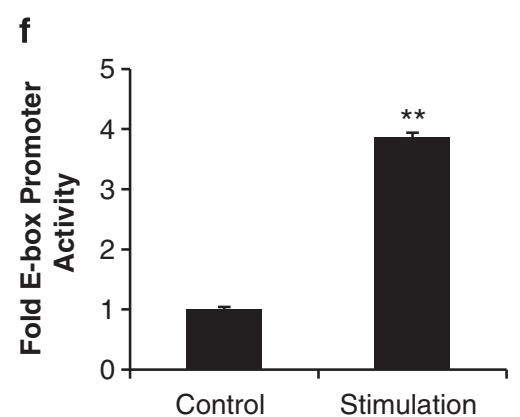

Figure 7 In vitro electrical stimulation of $\mathrm{RH} 30$ cells. (a) Western blot analysis revealed that electrical stimulation increased PKB/Akt activity and that this corresponded with increased phosphorylation of GSK3 $\beta$ at S9. Relative increase of phosphorylation at: (b) Akt at T308 and (c) GSK3 $\beta$ at S9, over time. Graphical representation of phosphorylated to total amounts of: (d) Akt and (e) GSK3 $\beta$. (f) E-box promoter activity decreased with electrical stimulation and this also corresponded with inhibition of GSK3 $\beta$ at $S 9$. ${ }^{*} P<0.01$, ${ }^{* *} P<0.001$

significance for understanding the etiology of this disease. Moreover, as repression of kinase activity is, in many cases, a tractable pharmacologic approach, we now propose targeting GSK3 $\beta$ activity as a tangible therapeutic strategy for ARMS.

In support of the above, a recent study showed that ARMSassociated PAX3/7-Foxo1 fusion proteins inhibit MYOD target genes. ${ }^{39}$ It was also reported that forced MYOD/Eprotein dimer expression could not rescue PAX3/7-Foxo1 repression of myogenic factors. ${ }^{39}$ Here, we also report that ectopically expressed PAX3-FOXO1 represses the induction of muscle genes, even when MRFs are expressed. We propose that the posttranslational repression of MYOGENIN 
activity is due to sustained GSK3 $\beta$ activity and, through a cross-talk mechanism, subsequent repression of p38 MAPK (Supplementary Figure 1) as we have previously described. ${ }^{10}$ p38 MAPK and PKB/Akt are both required for activation of MEF2/MYOD transcriptional control and chromatin remodeling events at crucial myogenic loci for the differentiation program. ${ }^{11,40}$

In other systems, GSK3 $\beta$ phosphorylation of its protein substrates results in subsequent targeting for proteasomal degradation. ${ }^{12,13}$ However, GSK3 $\beta$ does not appear to affect MYOGENIN protein stability in our experiments as we observe an increase in a slow migrating, hyperphosphorylated form of MYOGENIN in response to GSK3 $\beta$ signaling that is not reduced in terms of its level of expression suggesting that proteasomal degradation of MYOGENIN is not enhanced by GSK3 $\beta$. Conversely, neutralizing mutations of the GSK3 $\beta$ consensus enhanced MYOGENIN trans-activation of the muscle creatine kinase promoter, and also reduced the tumorigenic properties of ARMS cells $(\mathrm{RH} 30)$ in a colony-formation assay. These findings suggest that GSK3 $\beta$-mediated inhibition of MYOGENIN trans-activation properties impairs MYOGENIN's ability to promote terminal differentiation in tumorigenic $\mathrm{RH} 30$ cells.

Cell cycle control is an essential component of normal growth control and development which goes awry in tumorigenesis. To date several growth-promoting PAX3FOXO1 target genes have been implicated in RMS such as the IGF-R and c-Met although, while their contribution to proliferation is likely, the extent of their precise involvement in ARMS is still not clear. ${ }^{41}$ During normal skeletal myogenesis, upregulation of a cyclin-dependent kinase inhibitor, p21, stalls myoblasts in the $\mathrm{G} 2 / \mathrm{M}$ phase of the cell cycle thus priming them for differentiation by promoting cell cycle exit, which is a requirement for subsequent muscle-specific gene expression. ${ }^{42}$ Consistent with the idea that GSK3 $\beta$ activation may contribute to the oncogenic properties resulting from PAX3-FOXO1 expression in ARMS, we observed that the number of proliferative $\mathrm{RH} 30$ cells is approximately halved by pharmacological inhibition of GSK3 $\beta$. So far, the exact mechanism by which GSK3 $\beta$ regulates cell proliferation in ARMS is unknown. However, GSK3 $\beta$ has recently been shown to activate $\mathrm{KLF}^{43}$ and we recently identified that KLF6 enhances cell proliferation in myogenic cells through a TGF $\beta /$ Smad3 dependent pathway. ${ }^{44}$ We therefore speculate that PAX3-FOXO1/GSK3 $\beta$ enhancement of cell proliferation may involve KLF6 as a downstream effector as it is also highly expressed in various RMS cell types.

In summary, MYOGENIN normally activates genes that regulate cell fusion and terminal differentiation of skeletal muscle. In PAX3-FOXO1 expressing ARMS cells, our data indicate that sustained GSK3 $\beta$ activity represses MYOGENIN function, contributing to the transformed, proliferative phenotype of these cells. On the basis of this evidence, we propose that pharmacologic targeting of GSK3 $\beta$ kinase activity may constitute a tractable therapeutic strategy for ARMS.

Materials and Methods

Plasmids. E-box, MYOGENIN and MCK reporter constructs in pGL3 and expression vectors for MYOGENIN in EMSV were used in reporter gene assays.
HA-tagged PAX3-FOXO1 was cloned into pCDNA3.1 and kindly donated by Dr. Malkin at MaRS, Toronto. HA-tagged GSK3 $\beta(\mathrm{S} 9 \mathrm{~A})$ was cloned in pcDNA3 ORF $995-2305$.

Antibodies. Anti-MYOGENIN and anti-HA mouse monoclonal antibodies as well as anti-MEF2A rabbit polyclonal antibody were produced with the assistance of the York University Animal Care Facility; anti-PAX3 (1:250; Cell Signaling, Whitby, ON, Canada) GSK3 $\beta$, phospho-GSK3 $\beta$ (1:1000; Cell Signaling); actin, MYOD, Myf-5, GFP, dsRed2 (1:2000; SantaCruz, Santa Cruz, CA, USA) were used for immunoblotting experiments.

Cell culture and transfection. $\mathrm{C} 2 \mathrm{C} 12, \operatorname{Cos} 7$ and $\mathrm{RH} 30$ cells were maintained in DMEM supplemented with $10 \%$ fetal bovine serum (HyClone, Burlington, ON, Canada), 1\% L-glutamine and $1 \%$ penicillin-streptomycin. Cells were maintained in a humidified, $37^{\circ} \mathrm{C}$ incubator with a $5 \% \mathrm{CO}_{2}$ atmosphere. For transfections, cells were seeded 1 day before transfection and transfected according to the standard calcium phosphate method previously described. A mixture of $50 \mu \mathrm{l} 2.5 \mathrm{M} \mathrm{CaCl}_{2}$ per $25 \mu \mathrm{g}$ DNA with an equal volume of $2 x \mathrm{HeBS}$ (2.8 M NaCl, $15 \mathrm{mM} \mathrm{Na}_{2} \mathrm{HPO}_{4}, 50 \mathrm{mM} \mathrm{HEPES}, \mathrm{pH}=7.15$ ) was used and the cells were incubated overnight followed by washing and addition of fresh media. The cells were counted and transferred to pre-gelatin-coated plates.

Protein extractions, immunoblotting and reporter gene assays. Cells were collected using an NP-40 lysis buffer $(0.5 \%$ NP-40, $50 \mathrm{mM}$ Tris- $\mathrm{HCl}$ (pH 8.0), $150 \mathrm{mM} \mathrm{NaCl}, 10 \mathrm{mM}$ sodium pyrophosphate, $1 \mathrm{mM}$ EDTA (pH 8.0), $0.1 \mathrm{M} \mathrm{NaF}$ ) containing $10 \mu \mathrm{g} / \mathrm{ml}$ leupetin and aprotinin, $5 \mu \mathrm{g} / \mathrm{ml}$ pepstatin A, $0.2 \mathrm{mM}$ phenylmethylsulfonyl fluoride and $0.5 \mathrm{mM}$ sodium orthovanadate. Protein concentrations were determined using the Bradford method (Bio-Rad, Mississauga, ON, Canada) with bovine serum albumin (BSA) as a standard. An amount $20 \mu \mathrm{g}$ of total protein extracts were used for immunoblotting, diluted in sample buffer containing $5 \% \beta$-mercaptoethanol and boiled.

Transcriptional assays were done using luciferase reporter plasmids. The cells were collected for these assays using $20 \mathrm{mM}$ Tris, (pH 7.4) and $0.1 \%$ Triton-X 100 and the values obtained were normalized to $\beta$-galactosidase activity expressed from a constitutive SV40 driven expression vector and represented as relative light units $(\mathrm{RLU})$ or in some cases corrected Luciferase values for control, reporter alone transfections were arbitrarily set to 1.0 , and fold activation values were calculated. Bars represent the mean $(n=3)$ and error bars represent the standard error of the mean $(n=3)$. Independent two sample $t$-tests of all quantitative data were conducted using $R$ software. $P$-values are indicated with respect to controls where appropriate.

In vitro kinase assay. A total of $3 \mu \mathrm{g}$ of purified recombinant GST-MYOGENIN was mixed with either $0.5 \mu$ g purified recombinant GST-GSK3 $\beta$ (1-433; Cell Signaling) and with $\left(\gamma^{32} \mathrm{P}\right)$ ATP and incubated for $30 \mathrm{~min}$ at $30^{\circ} \mathrm{C}$. Samples were denatured for $5 \mathrm{~min}$ at $95^{\circ} \mathrm{C}$ in SDS sample buffer. Protein samples were then separated by $10 \%$ SDS-PAGE and exposed on X-ray film (Kodak X-Omat, Toronto, ON, Canada) for $21 \mathrm{~h}$ to detect ${ }^{32} \mathrm{P}$ incorporation. The lanes containing GST-MYOGENIN are elongated because two lanes were pooled to fit a higher total reaction volume to accommodate for the low concentration of purified GST-MYOGENIN $(0.06 \mu \mathrm{g} / \mu \mathrm{l})$. All lanes contain equal total amounts of proteins $(3 \mu \mathrm{g})$.

Electrical stimulation. Cells were plated onto $0.1 \%$ gelatin-coated 6 -well plates. The lids of the plates were fitted with two parallel platinum wire electrodes, placed at the opposite ends of each well and extending into the media. The wires from all wells were arranged in parallel and connected to an electrical stimulator (Harvard Apparatus Canada, Saint-Laurent, Quebec, Canada). Cells were stimulated at $5 \mathrm{~V}$ and a frequency of $5 \mathrm{~Hz}$ for 4 hours/day and allowed a subsequent $20 \mathrm{~h}$ recovery period. Cells were collected following the recovery period throughout the 4 days of the protocol.

Soft agarose colony-formation assay. Materials: $0.7 \%$ (w/v) DNA grade Agarose, 1\% (w/v) DNA grade Agar, 0.005\% Crystal Violet (Sigma-Aldrich, Oakville, ON, Canada), 2X Media $+20 \%$ (v/v) FBS. After $48 \mathrm{~h}$ of transfection with MYOGENIN containing the S160/164A mutations or empty vector, RH30 cells were assayed for their capacity to form colonies as previously described. ${ }^{45} \mathrm{~A}$ total of $1 \times 10^{4}$ cells were suspended on a layer of $0.35 \%$ agarose in DMEM $(10 \%$ FBS) with or without $10 \mu \mathrm{M}$ AR-A014418, in 6-well plates. Medium was refreshed every $3-5$ days as needed and on the $22 n d$ day, the amount of colonies were 
counted using a contrast phase microscope. The relative colony sizes were calculated using ImageJ software (Scion Corporation, Frederick, MD, USA). Four independent experiments were carried out in triplicate.

\section{Conflict of Interest}

The authors declare no conflict of interest.

Acknowledgements. We thank Dr. D Malkin from The Research Institute at The Hospital for Sick Children, Toronto, Ontario, Canada, for providing the HAPAX3-FOXO1 plasmids as well as the RH30 and RD cells. This work was supported by funding provided by Canadian Institutes for Health Research (CIHR) and Natural Sciences and Engineering Research Council of Canada (NSERC).

1. Galili N, Davis RJ, Fredericks S, Mukhopadhyay FJ, Rauscher BS III, Rovera EG et al. Fusion of a forkhead domain gene to PAX3 in the solid tumor alveolar rhabdomyosarcoma. Nat Genet 1993; 5: 230-235.

2. Barr FG. The role of chimeric paired box domain transcription factors in the pathogenesis of pediatric rhabdomyosarcoma. Cancer Res 1999; 59 (7 suppl): 1711s-1715s.

3. Paulino AC, Okcu MF. Rhabdomyosarcoma. Curr Probl Cancer 2008; 32: 7-34.

4. Buckingham M, Relaix $F$. The role of pax genes in the development of tissues and organs: PAX3 and Pax7 regulate muscle progenitor cell functions. Annu Rev Cell Dev Biol 2007; 23: $645-673$.

5. Buckingham M. Skeletal muscle progenitor cells and the role of Pax genes. C R Biol 2007; 330: $530-533$

6. Currie PD, Bryson-Richardson RJ. The genetics of vertebrate myogenesis. Nat Rev 2008; 9: $632-646$.

7. Han J, Molkentin J. Regulation of MEF2 by p38 MAPK and its implication in cardiomyocyte biology. Trends Cardiovasc Med 2000; 10: 19-22.

8. Muñoz JP, Collao A, Chiong M, Maldonado $C$, Adasme $T$, Carrasco $L$ et al. The transcription factor MEF2C mediates cardiomyocyte hypertrophy induced by IGF-1 signaling. Biochem Biophys Res Commun 2009; 388: 155-160.

9. de Angelis L, Zhao J, Andreucci JJ, Olson EN, Cossu G, McDermott JC. Regulation of vertebrate myotome development by the p38 MAP kinase-MEF2 signaling pathway. Dev Biol 2005; 283: 171-179.

10. Dionyssiou MG, Nowacki NB, Hashemi S, Zhao J, Kerr A, Tsushima RG et al. Cross-talk between glycogen synthase kinase $3 \beta$ (GSK3 $\beta$ ) and p38MAPK regulates myocyte enhancer factor 2 (MEF2) activity in skeletal and cardiac muscle. J Mol Cell Cardiol 2013; 54: 35-44.

11. Rampalli S, Li L, Mak E, Ge K, Brand M, Tapscott SJ et al. p38 MAPK signaling regulates recruitment of Ash2L-containing methyltransferase complexes to specific genes during differentiation. Nat Struct Mol Biol 2007; 14: 1150-1156.

12. Cohen P, Frame S. The renaissance of GSK3. Nat Rev 2001; 2: 769-776.

13. Doble BW, Woodgett JR. GSK-3: tricks of the trade for a multi-tasking kinase. J Cell Sci 2003; 116: 1175-1186

14. Sabourin LA, Rudnicki MA. The molecular regulation of myogenesis. Clin Genet 2000; 57 : $16-25$.

15. Grossi A, Yadav K, Lawson MA. Mechanical stimulation increases proliferation, differentiation and protein expression in culture: Stimulation effects are substrate dependent. J Biomech 2007; 40: 3354-3362.

16. Roeb W, Boyer A, Cavenee WK, Arden KC. PAX3-FOXO1 controls expression of p57Kip2 cell-cycle regulator through degredation of EGR1. Proc Natl Acad Sci USA 2007; 104: 18085-18090.

17. Yang Z, MacQuarrie KL, Analau E, Tyler AE, Dilworth FJ, Cao Y et al. MYOD and E-protein heterodimers switch rhabdomyosarcoma cells from an arrested myoblast phase to a differentiated state. Genes Dev 2009; 23: 694-707.

18. Puri PL, Wu Z, Zhang P, Wood LD, Bhakta KS, Han $\mathrm{J}$ et al. Induction of terminal differentiation by constitutive activation of p38 MAP kinase in human rhabdomyosarcoma cells. Genes Dev 2000; 14: 574-584.

19. Hasty P, Bradley A, Morris JH, Edmondson DG, Venuti JM, Olson EN et al. Muscle deficiency and neonatal death in mice with a targeted mutation in the MYOGENIN gene. Nature 1993; 364: 501-506.

20. Rawls A, Morris JH, Rudnicki M, Braun T, Arnold HH, Klein WH et al. MYOGENIN's functions do not overlap with those of MYOD or Myf-5 during mouse embryogenesis. Dev Biol 1995; 172: 37-50.

21. Megeney LA, Rudnicki MA. Determination versus differentiation and the MYOD family of transcription factors. Biochem Cell Biol 1995; 73: 723-732.

22. Weintraub AJ. The MYOD family and myogenesis: redundancy, networks and thresholds. Cell 1993; 75: 1241-1244.
23. Rudnicki MA, Braun T, Hinuma $S$, Jaenisch $R$. Inactivation of MYOD in mice leads to up-regulation of the myogenic $\mathrm{HLH}$ gene Myf-5 and results in apparently normal muscle development. Cell 1992; 71: 383-390.

24. Kassar-Duchossoy L, Gayraud-Morel B, Gomes D, Rocancourt D, Buckingham M, Shinin V et al. Mrf4 determines skeletal muscle identity in MYF5:MYOD double mutant mice. Nature 2004; 431: 466-471.

25. Kaul A, Koster M, Neuhaus H, Braun T. Myf-5 revisited: loss of early myotome formation does not lead to rib phenotype in homozygous Myf-5 mutant mice. Cell 2000; 102 : 17-19.

26. Rawls A, Valdez MR, Zhang W, Richardson J, Klein WH, Olson EN. Overlapping functions of the myogenic bHLH genes MRF4 and MYOD revealed in double mutant mice. Development 1998; 125: 2349-2358.

27. Kollias HD, Perry RLS, Miyake T, Aziz A, McDermott JC. Smad7 promotes and enhances skeletal muscle differentiation. Mol Cell Biol 2006; 26: 6248-6260.

28. Ornatsky OI, Cox DM, Tangirala P, Andreucci JJ, Quinn ZA, Wrana JL et al. Post-translational control of the MEF2A transcriptional regulatory protein. Nucleic Acids Res 1999; 27: 2646-2654.

29. Lluis F, Perdiguero E, Nebreda AR, Munoz-Canoves P. Regulation of skeletal muscle gene expression by p38 MAP kinases. Trends Cell Biol 2006; 16: 36-44.

30. Keren A, Bengal E, Frank D. p38 MAP kinase regulates the expression of XMYF5 and affects distinct myogenic programs during Xenopus development. Dev Biol 2005; 288: 73-86.

31. Du M, Perry RL, Nowacki NB, Gordon JW, Salma J, Zhao J et al. Protein kinase A represses skeletal myogenesis by targeting myocyte enhancer factor 2D. Mol Cell Biol 2008; 28: 2952-2970.

32. Raimondi L, Ciaarapica R, De Salvo M, Verginelli F, Gueguen M, Martini C et al. Inhibition of Notch3 signalling induces rhabdomyosarcoma cell differentiation promoting p38 phosphorylation and p21(Cip1) expression and hampers tumour cell growth in vitro and in vivo. Cell Death Differ 2012; 19: 871-881.

33. Connor MK, Irrcher I, Hood DA. Contractile activity-induced transcriptional activation of cytochrome c involves Sp1 and Is proportional to mitochondrial ATP synthesis in $\mathrm{C} 2 \mathrm{C} 12$ muscle cells. J Biol Chem 2001; 276: 15898-15904.

34. Cross DA, Alessi DR, Cohen P, Andjelkovich M, Hemmings BA. Inhibition of glycogen synthase kinase-3 by insulin mediated protein kinase B. Nature 1995; 378: 785-789.

35. Davis RJ, D'Cruz CM, Lovell MA, Biegel JA, Barr FG. Fusion of PAX7 to FKHR by the variant $\mathrm{t}(1 ; 13)(\mathrm{p} 36 ; q 14)$ translocation in alveolar rhabdomyosarcoma. Cancer Res 1994; 54: 2869-2872.

36. Tonin PN, Scrable H, Shimada H, Cavenee WK. Muscle-specific gene expression in rhabdomyosarcomas and stages of human fetal skeletal muscle development. Cancer Res 1991; 51: 5100-5106.

37. Dias $\mathrm{P}$, Chen B, Dilday B, Palmer H, Hosoi H, Singh $\mathrm{S}$ et al. Strong immunostaining for MYOGENIN in rhabdomyosarcoma is significantly associated with tumors of the alveolar subclass. Am J Pathol 2000; 156: 399-408.

38. Sebire NJ, Malone M. MYOGENIN and MYOD1 expression in paediatric rhabdomyosarcomas. J Clin Pathol 2003; 56: 412-416.

39. Calhabeu F, Hayashi S, Morgan JE, Relaix F, Zammit PS. Alveolar rhabdomyosarcomaassociated proteins PAX3/FOX01A and PAX7/FOXO1A suppress the transcriptiona activity of MYOD-target genes in muscle stem cells. Oncogene 2013; 32: 651-662.

40. Serra C, Palacios D, Mozzetta C, Forcales SV, Morantte I, Ripani M et al. Functional interdependence at the chromatin level between the MKK6/p38 and IGF1/PI3K/AKT pathways during muscle differentiation. Mol Cell 2007; 28: 200-213.

41. Keller C, Guttridge DC. Mechanisms of impaired differentiation in rhabdomyosarcoma. FEBS J 2013; 17: 4323-4334.

42. Gurung R, Parnaik VK. Cyclin D3 promotes myogenic differentiation and Pax7 transcription. J Cell Biochem 2012; 113: 209-219.

43. Lang UE, Kocabayoglu P, Cheng GZ, Ghiassi-Nejad Z, Munoz U, Vetter D et al. GSK3 $\beta$ phosphorylation of the KLF6 tumor suppressor promotes its transactivation of p21. Oncogene 2012; 32: 4557-4564.

44. Dionyssiou MG, Salma J, Bevzyuk M, Wales S, Zakharyan L, McDermott JC. Kruppel-like factor 6 (KLF6) promotes cell proliferation in skeletal muscle cells in response to TGF $\beta /$ Smad3 signaling. Skelet Muscle 2013; 3: 7.

45. Ciarapica R, Annibali D, Raimondi L, Savino M, Nasi S, Rota R. Targeting Id protein interactions by an engineered $\mathrm{HLH}$ domain induces human neuroblastoma cell differentiation. Oncogene 2009; 28: 1881-1891.

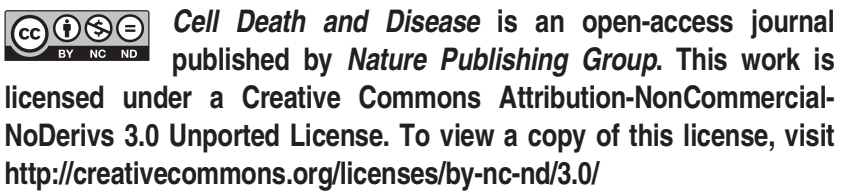

